\title{
Cognitive Load and Learning Styles of Mobile Workers: Future Directions
}

\author{
Sonia Jeddi and Samia Karoui Zouaoui \\ University of Tunis El Manar, Tunis, Tunisia
}

\begin{abstract}
The wide use of mobile information and communication technologies in working practices offers new opportunities to workers to absorb and process information in different ways, different places and consequently to support their learning anytime anywhere. However, owing to this mobilization, mobile devices contribute to work intensification and at the end lead to the development of information overload problems.

Recent mobility literature misses a theoretical and empirical explanation of the individual and organizational impact of this emerging concept, we thus propose in the current research to explain the relationship between worker's mobility and the learning styles through enhancing the information load. The results of semi-structured interviews with Tunisian mobile workers reveal that the use of mobiles ICT can generates paradoxical styles of learning. This is essentially due to individual cognitive capacity, the nature (urgent or ordinary), the moment (beginning or end of day) and solicitations.

Researches on learning styles in the Information System area should be further developed, especially with regard to the analysis of overload of mobile workers. Cognitive issues and the awareness of the way mobile workers assimilate and use information can offer new individual and organizational opportunities to face mobility challenges. It will also provide us with a useful framework for future researches.
\end{abstract}

Keywords: mobile technology, mobile workers, learning styles, information overload.

\section{Introduction}

Use of wireless technology and mobile devices increases the need of flexibility for organizations and creates an increasingly nomadic management. One of the main reasons of technologies adoption is their important role as a facilitator of acquiring, sharing and diffusing knowledge among organizations (Goodman and Darr 1998; Broendsted and Elkjaer, 2001). Hence, they enable organizations to have knowledge capital and improve their learning skills.
Indeed, learning of organization or of its members is considered as the key variable of the performance and competitiveness. More important, and according to Laru and Järvelä (2004), one of the most significant mechanisms through which learning is transformed today, is technology.

A literature review shows that researches on organizational impact of ICT were extensive (Gill, 1995; Kleinrock, 1995; Isaac, Campoy

Copyright (C) 2011 Sonia Jeddi, and Samia Karoui Zouaoui. This is an open access article distributed under the Creative Commons Attribution License unported 3.0, which permits unrestricted use, distribution, and reproduction in any medium, provided that original work is properly cited. Contact author: Sonia Jeddi e-mail: jeddisonia@yahoo.fr 
and Kalika, 2006). However, although the proliferation of researches on the effects of organizational mobile technology, the effects appear to be complex (Besseyre Des Horts, 2006). In this perspective, our goal is to understand the relationship between managers learning styles and their use of mobile devices. Compared to traditional office work (stationary), working with mobile technology presents new individual challenges. The remarkable increase in information flow has posed the problem of user's limited cognitive capacities. They are often forced to adapt to glut information which is generally irrelevant. They MAY consequently suffer from information overload.

In this paper we focus on the question of the impact of increased amount of information on mobile worker's learning styles. As cognitive resources determine individual level of learning (Cangelosi and Dill, 1965; Argyris, 1977), it would be interesting to know if mobile workers have any specifics in terms of learning style. Answering this question requires an analysis of the cognitive profile of the workers. Indeed, each person has a cognitive profile which can help him to develop his learning skills (Webster, 2004). Analysis of the context and conditions for using mobile technology should be conducted too.

The paper will be structured as follows. Section one will revisit the relationship between use of ICT and worker's mobility in current academic discourse. Section two discusses the learning styles and why mobile devices can transform styles. The third Section concerns mobility and ubiquity of work and especially how they have brought into THE focus of information overload problems. In conclusion, we will propose the theoretical and the methodological issues surrounding mobility.

\section{Worker's Mobility Background}

Mobile technologies are becoming more embedded, ubiquitous and networked, with enhanced capabilities for rich social interactions, context awareness and internet connectivity (Kleinrock, 1995). Importance of mobility and potential value of 'being mobile' are understood, but issues surrounding mobility are still explored without any clear understanding of mobility itself (Argyris, 1977).

This ambiguity is relevant to the difficulty to explain mobility. For example, Kristofferson and Ljungberg (1999), argue it is impossible to define "mobility" in a meaningful way. In an effort of conceptualization mobility and IT use, the authors proposed three modalities of mobility and introduced a model with three components: environment, modalities and intention. Modalities of mobility are conceived as being stationary, walking, wandering, travelling or visiting. Luff and Heath (1998), identified Micro, Local and Remote mobilities. The first one is related to moveable artifacts for various purposes. The second one is due to the mobility of people between rooms, floors and buildings at a particular location. Remote mobility is related to the mobility of users between different sites and implies interaction with other remote users. For Kakihara and Sørensen (2001) and Basole (2004), mobility should be defined along spatial, temporal, and contextual dimensions. The context refers to the way, circumstance and situation in which mobile workers execute their activities. Spatiality involves the movement of workers, devices and documents in different geographical locations. Temporal dimension involves period, sequence and time allocation of activities. Pica \& Kakihara (2003) however recommended a distinction between "mobile" which refers to the state where an entity - whether physical, nonphysical, tangible or intangible - can move or be moved, and between "mobility" which refers to the ability for achieving it (Basole, 2004). Table 1 bellow represents all these classifications, with their appropriate functions and technology's patterns. 
Table 1: Modalities of Mobility with Assimilated Workers and Technologies

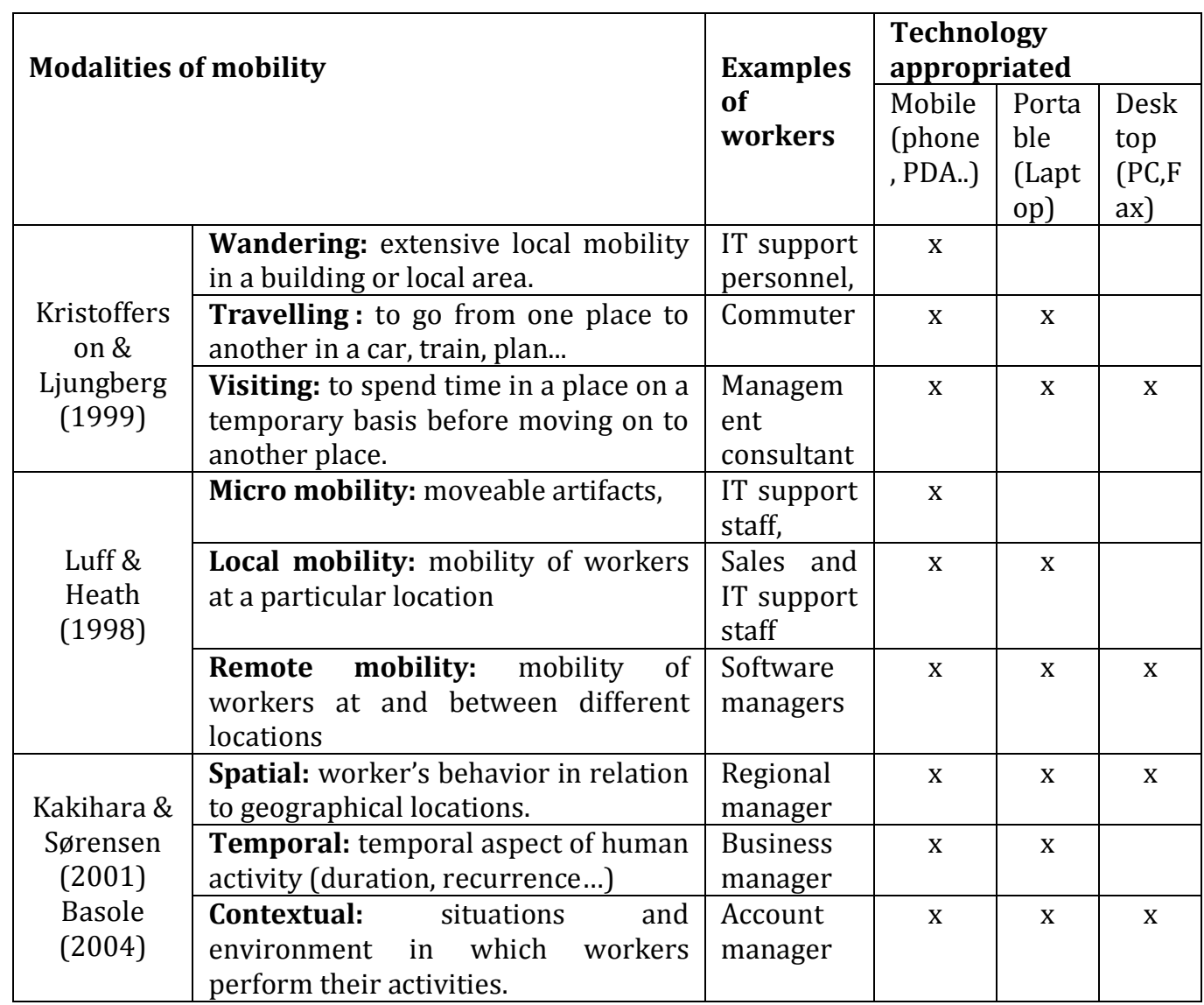

Furthermore, distinction is essential between "mobile worker" and "nomad worker". Our literature review shows that both expressions are often used interchangeably. Kleinrock (1995), defines nomads as workers who use computer and communication devices to access remote information from their home bases, in transit, and at destinations. Chen and Nath (2005), used this definition to conclude that nomadic workforce scope is broader than mobile workforce's one. By this way, nomads are characterized by either a higher level of mobility or a greater distance from the traditional office, and in some cases by both of them. Thereby, mobile worker is always a nomadic one, but nomadic worker is not necessarily a mobile one.
Within our research, and since we recognize that mobile technologies are tools providing access to information, data, and persons in a ubiquitous way, we admit that mobile workers are users that are most of the time on the move. They have the possibility to work away from the office and to access to information anytime, anywhere.

Several technologies can be classified as mobile ones. As outlined in Figure 1, Naismith et al. (2004), use personal versus shared and portable versus static dimensions to classify mobile technologies. In quadrant 1 there are examples of personal portable technologies (mobile phones, PDAs, tablet PCs, laptops, game consoles). These devices can be taken from place to place and can be 
available in many different sites. Personal static technologies figure in quadrant 2 . They consist on individual student devices that are used to respond anonymously to multiple choice questions. In quadrant 3 , authors expose technologies that can provide learning experiences to mobile workers users with devices not physically movables (Street kiosks, interactive museum displays). Quadrant 4 includes technologies that can support and complete possibilities of communication offered by the ones already cited (interactive classroom whiteboards and video-conferencing facilities).

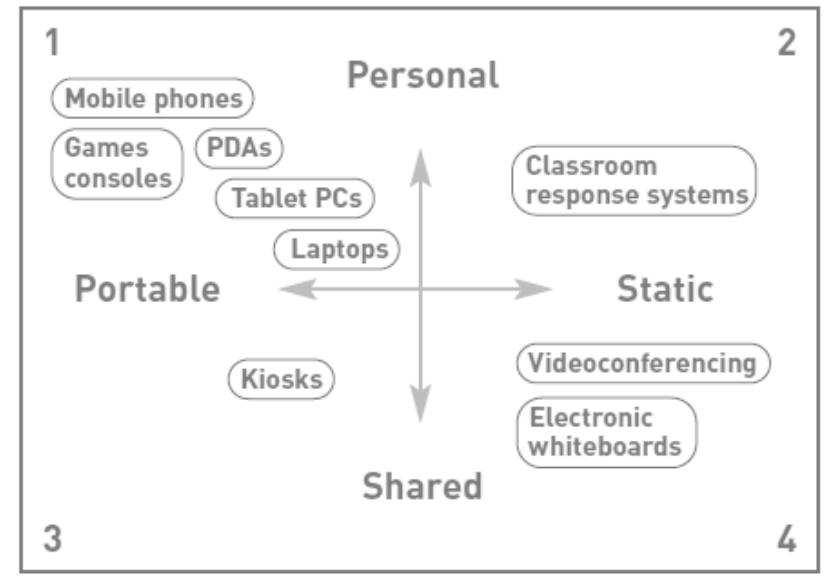

Figure 1: Classification of Mobile Technologies (Naismith et al., 2004)

In this research, we will be limited to devices both personal and portable (quadrant 1). Sharples, Corlett and Westmancott (2002), think learning is a contextual activity. Therefore, it depends heavily on technology to both mobile and personal as they can support learning anytime anywhere. Among the technologies classified, we will limit to laptops, PDAs and mobile phones. These media provide independence of worker and offer the possibility to communicate synchronously.

Furthermore, they are the most used technologies by mobiles managers we interviewed in our exploratory study. Seventeen males have participated. They are ranged between 23-37 years old. We could conclude interviewers are very dependent on their mobile phones. According to them, it is the easy way to join colleagues, customers, suppliers. Mobile phone use is followed by laptops use, since for workers e-mail remains a second source of information, it may even in some cases replace the phone.

\section{Learning Styles and Worker's Mobility}

Mobile devices have enabled the emergence of a variety of new communication and coordination behaviors (Goodman and Darr, 1998). Users have consequently possibilities to absorb and process information in different ways and in different places. Thus, for the same activity, some will prefer the visual mode (image and document analysis), others will prefer the auditory mode (listening, dialoguing ...) and others will choose the kinesthetic one (gestures and physical exercise). So that, concept of learning style was used to understand user's preferences for their learning activities and the way these preferences can optimize the effectiveness of learning process. According to Felder and Spurlin (2005), learning styles are generally defined as differences on individual preferences and strengths in the ways they take in and process information. Keefe (1979) describes learning styles as the characteristic cognitive, emotional, and psychological behaviors that serve as 
relatively stable indicators of how learners perceive, interact with, and respond to the learning environment. Note that many studies use the terms "cognitive styles" and "learning styles" interchangeably. However, learning style has always been the appropriate term to match learning with cognitive or personality characteristics of the learners.

Three leading theorists have examined this concept: the theories of Kolb (1981), Honey and Mumford (1982) and Felder and Silverman (1988). Each proposes different classifications and index of learning styles. Kolb (1981) used a four quadrant model for identifying four types of learners: Diverging (perform better in situations that require ideas-generation), Assimilating (prefer to work with ideas and abstract concepts), Converging (prefer technical tasks and practical applications), and Accommodating (prefer to rely on intuition rather than logic.). Honey and Mumford learning style model (1982) identifies four different preferred learning styles: activist (learn best from novel experiences), reflector (prefer to reflect about tasks before acting), theorist (prefer to work with system, model, concept or theory), and pragmatist (prefer to act and to deal with practical applications). The Felder-Silverman learning style model (Felder and Silverman, 1988), which is used very often in research related to learning styles in electronic learning environments, details this concept and distinguishes between four symmetric dimensions: active (prefer to try things before acting) versus reflective (prefer to think about things quietly) learners, sensing (Like learning facts) versus intuitive (prefer discovering possibilities and relationships) learners, visual (prefer to deal with visual representations) versus verbal learners (prefer written and spoken explanations), sequential (prefer learn in small incremental steps) versus global learners (prefer learn in large leaps).

The study of Vavoula (2005) showed that $52 \%$ of everyday learning episodes involved one or more pieces of electronic technology: mobile and fixed phones, laptop and desktop computers, televisions and video recorders. Despite the new paradigm "anytime, anywhere computing" (Kakihara and Sorensen, 2001), theoretical, methodological and empirical understandings of impact of mobility on learning style are still at rather early stage. In order to optimize the learning experience of mobile workers, researchers should study the dialectical relationship between transformation of learning style and use of mobile devices. It would be interesting to explore this relationship with this rapid and accelerating move towards the adoption and use of mobile technology.

This question is also important with the phenomenon of juxtaposition of media and the misuse of technological tools. In fact, access to so much information and the risk of misinformation generate an information overload of receivers. Although this phenomenon has several causes, we note that Information and Communication Technology remains the major one (Chewning E.C. and Harrell, 1990). Bellow, we expose this major cognitive problems generated by excessive quantity of information provided by ICT.

\section{Information Overload Worker's Mobile}

Mobile IT use generates ubiquity of work. All activities can be executed everywhere (home, train, plane ...) and at every time (during holidays, weekends, pause ...). Thanks to new possibilities of communication, coordination and collaboration, learning difficulties can be overcome. However, new challenges are able to emerge. By mobilizing the learners, mobile devices can contribute to work intensification. The information overload is seen as the work intensifying factor that has taken a considerable extent with the development of networks and mobile (Vendramin and Valenduc, 2005).

This concept has been undertaken in the areas of accounting (Schick, Gordon and Haka, 1990; Chewning and Harrell, 1990), of marketing (Braun-LaTour, Puccinelli and 
Mast, 2007), of psychology (HjØrland, 1984), of Management Information Systems (Pica and Kakihara, 2003; Isaac, Campoy and Kalika, 2006). All these Researches focused on individual difficulties and their inability to process tasks due to a huge number of circulating information., they specifically stressed on how individual performances correlate according to the amount of information received. For our case, and in addition to the "classical" definition of information overload, this phenomenon is also the result of worker's combination of desktop and mobile technologies. Indeed, users dispose of a portfolio of technological tools (mobile phone, fax, email, PDA, telephone, sms ...) and consequently must manage many interruptions and many responsibilities. Findings of O'Hara et al. (2001) show that documents (paper and electronic format) are still used by mobile workers. They explain that paper has important characteristics that make it useful for opportunistic appropriation in a range of circumstances both predictable and unpredictable.

To treat all information received from multiple sources, the individual will apply his cognitive resources. According to the theory of Sweller (1988), use of ICT can enhance and often create many cognitive problems during learning. This is essentially due to big amount of information offered to users, and also to time waste to find pertinent information. This phenomenon acts negatively on cognitive system and consequently slows or at least hinders the learning process.

During the last three decades, researchers have examined the characteristics of learning styles at five levels of particular behavior: Personality types, early educational specialization, professional career, current job role and adaptive competencies (Kolb, Boyatzis R., and Mainemelis, 2001). However, much of these researches, especially in MIS area, have given little attention to influencing cognitive factors on process of learning in general. Given that learning style is a cognitive process, it would be interesting to understand the way it is influenced by learner's cognitive load increase especially with extensive use of ICT.

Based on our primary exploration in some Tunisian companies (telecommunications operator, multinational communications corporation...), we have remarked that in situations of overload, visual learning is becoming the preferred mode of learning. Mobile workers tend to assimilate more easily what they see to what they hear. This besides explains the lack of communication between colleagues in case of overload. Furthermore, we found that working with paper documents would be the preferred means of saturated workers, in contrast to cases where they can manage information flows.

In this regard, use of mobiles ICT can generate paradoxical styles of learning. Given the same situation, learners would report contrasted styles. This is due to individual differences, cognitive capacities and nature (urgent or ordinary), moment (beginning or end of day) and amount of solicitations. Thus, at the beginning of the day, and with minimal solicitation, individuals tend to be concentrated and to do work satisfactorily. They seem to have enough time to discuss together and to consider all the implications of taken decisions. This scene corresponds to active and reflective style of Felder-Silverman (1988), to "collaborative style work" of Grasha Riechmann (1974), or to reflective style of Honey \& Mumford (1986). During the day, as solicitations, interruptions frequencies and amount of work increase, the concentration is divided between multiple tasks and multiple media. Operators never seem to have enough time to get everything done. These situations correspond to impulsive style (Jerome Kagan \& Pearson, 1966), independent style of Grasha-Riechmann (1974), and style based on "scanning" (Bruner, 1956). We synthesize theses paradoxical effects of learning styles in table below. 
Table 2: Contrasted Learning Styles of Mobile Workers

\begin{tabular}{|c|l|l|}
\hline & \multicolumn{1}{|c|}{ Accelerated pace of work } & \multicolumn{1}{c|}{ Smoothly pace of work } \\
\hline $\begin{array}{c}\text { Learning style } \\
\text { appropriated }\end{array}$ & $\begin{array}{l}\text { Impulsive style (Jerome Kagan \& } \\
\text { Pearson, 1966), } \\
\text { Independent style (Grasha- } \\
\text { Riechmann, 1974) } \\
\text { Style based on "scanning" } \\
\text { (Bruner, 1956). }\end{array}$ & $\begin{array}{l}\text { Active and reflective style (Felder- } \\
\text { Silverman, 1988) } \\
\text { Collaborative style work (Grasha } \\
\text { Riechmann, 1974), } \\
\text { Reflective style (Honey \& Mumford, } \\
1986) .\end{array}$ \\
\hline $\begin{array}{c}\text { Tool } \\
\text { appropriated }\end{array}$ & $\begin{array}{l}\text { Individuals prefer to deal } \\
\text { especially with paper documents }\end{array}$ & $\begin{array}{l}\text { Electronic communication (mobile } \\
\text { phone, email ...) }\end{array}$ \\
\hline $\begin{array}{c}\text { Perceptual } \\
\text { channel }\end{array}$ & $\begin{array}{l}\text { Visual and kinesthetic mode of } \\
\text { learning (analysis of an image of a a } \\
\text { paper ...) }\end{array}$ & $\begin{array}{l}\text { Auditory mode of learning } \\
\text { (listening, dialogue ...) }\end{array}$ \\
\hline
\end{tabular}

\section{Conclusion}

The purpose of the current research is to explore the relationship between worker's mobility and transformation of learning style through enhancing the information load. With their new offered possibilities to diffuse and share information, mobile technologies can be essential in supporting learning. However, increasing rate of new information can overwhelmed workers and negatively impact their preferred way to absorb, represent and process information and thus at the end their ways to learn. Interviews with Tunisian mobile workers confirm that, for the same charge or mission, workers learn in different ways and the manners vary when they are overwhelmed.

The impact of mobile ICT in working practices has been the focus of several research and scientific studies. However, the way mobility is discussed and conceptualized in mobile HCI (Hagen, Robertson and Sadler, 2005 ) is not detailed enough. In this regard, many issues should be resolved. Researches on learning styles in the MIS area should be further developed, especially with regard to the analysis of overload of mobile workers.
The cognitive way seems to be particularly promising for achieving our goal. Owing to the organization and the representation of the collected information from semistructured interviews, mind-maps seem to be of relevant tools. Indeed, learning styles and information overload are closely related to mental models of learners. Categorizing this relationship can offer new individual and organizational opportunities to face challenges of mobility. It will certainly provide us with a useful framework for future researches.

\section{References}

Argyris, C. (1977). "Organizational Learning and Management Information Systems," Accounting, Organizations and Society Vol. 2, No. 2, pp. 113-123.

Basole, R. C. (2004). "The Value and Impact of Mobile Information and Communication Technologies," Retrieved Mai 18, 2008, from: http://www2.isye.gatech.edu/tidev/docs/Ba soleIFAC2004MobileEnterprises.pdf. 
Besseyre, D. \& Isaac, H. (2006). 'L'impact des TIC Mobiles sur les Activités Professionnelles en Entreprise,' Revue française de gestion, (168-169), 2006, pp. 243-263.

Braun-LaTour, K. A., Puccinelli, N. M. \& Mast, F. W. (2007). "Mood, Information Congruency, and Overload," Journal of Business Research. doi:10.1016/j.jbusres.2007.04.003.

Broendsted, J. \& Elkjaer, B. (2001). 'Information Technology as a Follow Player in Organizational Learning,' Proceedings of the 9th European Conference on Information Systems, Bled, Slovenia, June 27-29, pp. 687695.

Cangelosi, V. E. \& Dill, W. R. (1965). "Organizational Learning: Observations toward a Theory," Administrative Science Quarterly, 10, 175-203.

Chen, L. \& Nath, R. (2005). "Nomadic Culture: Cultural Support for Working Anytime, Anywhere," Information Systems Management, Fall, p. 56-64.

Chewning, E. C. \& Harrell, A. M. (1990)."The Effect of Information Load on Decision Makers' Cue Utilization Levels and Decision Quality in a Financial Distress Decision Task," Accounting, Organizations and Society, (15:6), $\mathrm{pp}$ 527-542.

Eppler, M. J. \& Mengis, J. (2003). "A Framework for Information Overload Research in Organizations," The Information Society, informaworld.com . 42 pages

Felder, R. M. \& Silverman, L. K. (1988). "Learning and Teaching Styles in Engineering Education," Journal of engineering education, (78:7), pp. 674-681.

Felder, R. M. \& Spurlin, J. (2005). "Applications, Reliability and Validity of the Index of Learning Styles," International Journal of Engineering Education, (21:1), pp. 103-112.
Gill, T. G. (1995). "High-Tech Hidebound: Case Studies of Information Technologies that Inhibited Organizational Learning," Accounting Management and Information Technology, (5:1), , pp. 41-60.

Goodman, P. S. \& Darr, E. D. (1998). "Computer-Aided Systems and Communities: Mechanisms for Organizational Learning in Distributed Environments," MIS Quarterly, (22:4), pp. 417-440.

Hagen, P., Robertson, T., Kan, M. \& Sadler, K. (2005). "Emerging Research Methods for Understanding Mobile Technology Use," Proeedings of CHISIG Australia 2005, pp. 110.

HjØrland, B. (1984). "Psychology and Information Search Strategy: Information Input Overload," Social Science Information Studies, (4), pp. 143-l 48.

Isaac, H., Campoy, E. \& Kalika, M. (2006). "Surcharge Informationnelle, Urgence et TIC: L'effet temporel des technologies de l'information," Revue Management et Avenir, pp. 153- 172 .

Kakihara, M. \& Sorensen, C. (2001). "Expanding the Mobility Concept," ACM SIGGROUP Bulletin, pp. 33-37.

Kolb, D. A. (1981). 'Learning Styles and Disciplinary Differences,' The Modern American College. (Edited by A.W. Chickering, Jossey-Bass, San Francisco). pp. 233-255.

Kolb, D. A., Boyatzis, R. E. \& Mainemelis, C. (2001). "Experiential Learning Theory: Previous Research and New Directions," R. Sternberg \& L. Zhang (Eds.), Perspectives on cognitive learning, and thinking styles, , pp. 228-247.

Kleinrock, L. (1995). "Nomadic Computing: An Opportunity," Computer Communication Review, pp. 36-40.

Kristoffersen, S. \& Ljungberg, F. (1999). "Mobile Use of IT," Proceedings of the 22nd 
Information Systems Research Seminar in Scandinavia Conference.

Laru, J. \& Järvelä, S. (2004). "Scaffolding Different Learning Activities with Mobile Tools in Three Everyday Contexts," Instructional Design for Effective and Enjoyable Computer-Supported Learning, pp. 11-21.

Luff, P. \& Heath, C. (1998). "Mobility in Collaboration," Proceedings of CSCW'98. November 14 -18, Seattle. pp. 305-314.

Naismith, L., Lonsdale, P., Vavoula, G. \& Sharples, M. (2004). "Literature Review in Mobile Technologies and Learning," Nesta Futurelab Series, report 11.

O’Hara, K., Perry, M., Sellen, A. \& Brown, B. A. T. (2002). "Exploring the Relationship between Mobile Phone and Document Use during Business Travel," Presented at the Wireless World: social and interactional implications of the mobile age, pp.1-9.

Pica, D. \& Kakihara, M. (2003). 'The Duality of Mobility: Designing Fluid Organizations through Stable Interaction,' Proceedings of the 11th European Conference on Information Systems (ECIS 2003). Naples, Italy. 19th-21st June 2003.

Schick, A. G., Gordon, L. A. \& Haka, S. (1990). "Information Overload: A Temporal Approach," Accounting, Organizations and Society, (15:3), pp. 199-220.

Sharples, M, Corlett, D. \& Westmancott, 0. (2008). "The Design and Implementation of a Mobile Learning Resource," Personal and Ubiquitous Computing. Retrieved October 13, from

http://www.eee.bham.ac.uk/sharplem/Pape rs/mobile\%20learning\%20puc.pdf

Vendramin, P. \& Valenduc, G. (2005). "Les Tensions du Temps," Dossier éducation permanente, juin.

Webster, R. (2004). "Interfaces for Elearning: Cognitive Styles and Software
Agents for Web-Based Learning Support," Retrieved August 24, from http://www.medfac.unimelb.edu.au/ascilite 2001/pdf/papers/websterr.pdf 